\title{
Complete genome sequence of Candidatus Ruthia magnifica
}

Guus Roeselers ${ }^{1,2}$, Irene L. G. Newton ${ }^{1,3}$, Tanja Woyke ${ }^{4}$, Thomas A. Auchtung ${ }^{1}$, Geoffrey F. Dilly ${ }^{1}$, Rachel J. Dutton ${ }^{5}$, Meredith C. Fisher ${ }^{1}$, Kristina M. Fontanez ${ }^{1}$, Evan Lau ${ }^{1}$, Frank J. Stewart ${ }^{1}$, Paul M. Richardson ${ }^{4}$, Kerrie W. Barry ${ }^{4}$, Elizabeth Saunders ${ }^{4}$, John C. Detter ${ }^{4}$, Dongying $\mathrm{Wu}^{6}$, Jonathan A. Eisen ${ }^{6}$, Colleen M. Cavanaugh ${ }^{1 *}$

${ }^{1}$ Harvard University, Department of Organismic and Evolutionary Biology, 16 Divinity Avenue, Biolabs 4080, Cambridge, MA 02138, USA.

${ }^{2}$ Radboud University, Department of Microbiology, Heyendaalseweg 135, 6525 AJ Nijmegen, The Netherlands.

${ }^{3}$ Department of Biological Sciences, 106 Central St, Wellesley, MA 02482, USA.

${ }^{4}$ Department of Energy Joint Genome Institute, 2800 Mitchell Drive, Walnut Creek, CA 94598, USA.

${ }^{5}$ Harvard Medical School, Department of Microbiology and Molecular Genetics, 200 Longwood Avenue, Boston, MA 02115, USA.

${ }^{6}$ University of California, Davis Genome Center, Genome and Biomedical Sciences Facility, Room 5311, 451 East Health Sciences Drive, Davis, CA 95616-8816, USA.

*Corresponding author email: cavanaug@fas.harvard.edu

Keywords: Hydrotheral vent; Clam; sulfur; symbiosis; chemosynthesis, vesicomyidae

The hydrothermal vent clam Calyptogena magnifica (Bivalvia: Mollusca) is a member of the Vesicomyidae. Species within this family form symbioses with chemosynthetic Gammaproteobacteria. They exist in environments such as hydrothermal vents and cold seeps and have a rudimentary gut and feeding groove, indicating a large dependence on their endosymbionts for nutrition. The C. magnifica symbiont, Candidatus Ruthia magnifica, was the first intracellular sulfur-oxidizing endosymbiont to have its genome sequenced (Newton et al. 2007). Here we expand upon the original report and provide additional details complying with the emerging MIGS/MIMS standards. The complete genome exposed the genetic blueprint of the metabolic capabilities of the symbiont. Genes which were predicted to encode the proteins required for all the metabolic pathways typical of free-living chemoautotrophs were detected in the symbiont genome. These include major pathways including carbon fixation, sulfur oxidation, nitrogen assimilation, as well as amino acid and cofactor/vitamin biosynthesis. This genome sequence is invaluable in the study of these enigmatic associations and provides insights into the origin and evolution of autotrophic endosymbiosis.

Abbreviations: JCVI- J. Craig Venter Institute, JGI- Joint Genome Institute, NCBI- National Center for Biotechnology Information, TIGR- The Institute for Genomic Research

\section{Introduction}

Chemosynthetic symbioses, initially discovered at hydrothermal vents, also exist in shallow mud flats and seagrass beds, and deep sea cold methane seeps [1]. In each case it is clear that these symbioses play major roles in community structuring and sulfur and carbon cycling. However, despite the widespread occurrence of these partnerships, little is known of the intricacies of hostsymbiont interaction or symbiont metabolism due to their inaccessibility and our inability to culture either partner separately.

The giant clam, Calyptogena magnifica Boss and Turner (Bivalvia: Vesicomyidae), was one of the first organisms described after the discovery of hydrothermal vents. Vesicomyidae is a relatively old family, with fossil records and phylogenies dating them at 50-100 Ma [2]. C. magnifica grows to a large size ( $>26 \mathrm{~cm}$ in length), despite having a 
reduced gut and ciliary food groove [3], presenting a conundrum regarding how it acquires sufficient nutrients. The discovery of chemoautotrophic, Gammaproteobacterial endosymbionts, now named Candidatus Ruthia magnifica (in memory of Prof. Ruth Turner), within C. magnifica gill bacteriocytes $[4,5]$ helped to solve the mystery surrounding the nutrition of this clam. The host depends largely on these endosymbionts for its carbon, as indicated by its anatomy and by stable carbon isotopic ratios [6]. However, how the host satisfies the rest of its nutritional requirements remained unknown.

Vesicomyid symbionts are presumed to be obligately symbiotic as they have a relatively reduced genome size [7-9], and are transmitted vertically between successive host generations via the egg [10]. Evidence has been presented indicating a single Gammaproteobacterial symbiont is present in vesicomyids that have been examined via rRNA phylotyping [11]. However recent evidence suggests that vesicomyids may harbor two symbiont phylotypes, both of which fall into the same clade but are distinct phylotypes. Thus the clams may acquire divergent symbionts laterally via uptake from an environmental population or horizontal transfer from co-occurring hosts [12].

Here we present a classification and a set of features (Figure 1, Figure 2, Table 1) for Candidatus R. magnifica, together with a description of the complete genome sequence and annotation originally presented in [9].

\section{Organism information}

Candidatus Ruthia magnifica is the chemosynthetic gill endosymbiont of the giant clam, Calyptogena magnifica Boss and Turner (Bivalvia: Vesicomyidae) (Figure 1). Vesicomyid clams are conspicuous fauna at many deep-sea hydrothermal-vent and cold-seep habitats. Candidatus R. magnifica, a member of the phylum Gammaproteobacteria, falls within the vesicomyid symbiont clade which is a sister group to vent and seep mussel chemosynthetic symbionts of the subfamily Bathymolidinae (Figure 2).

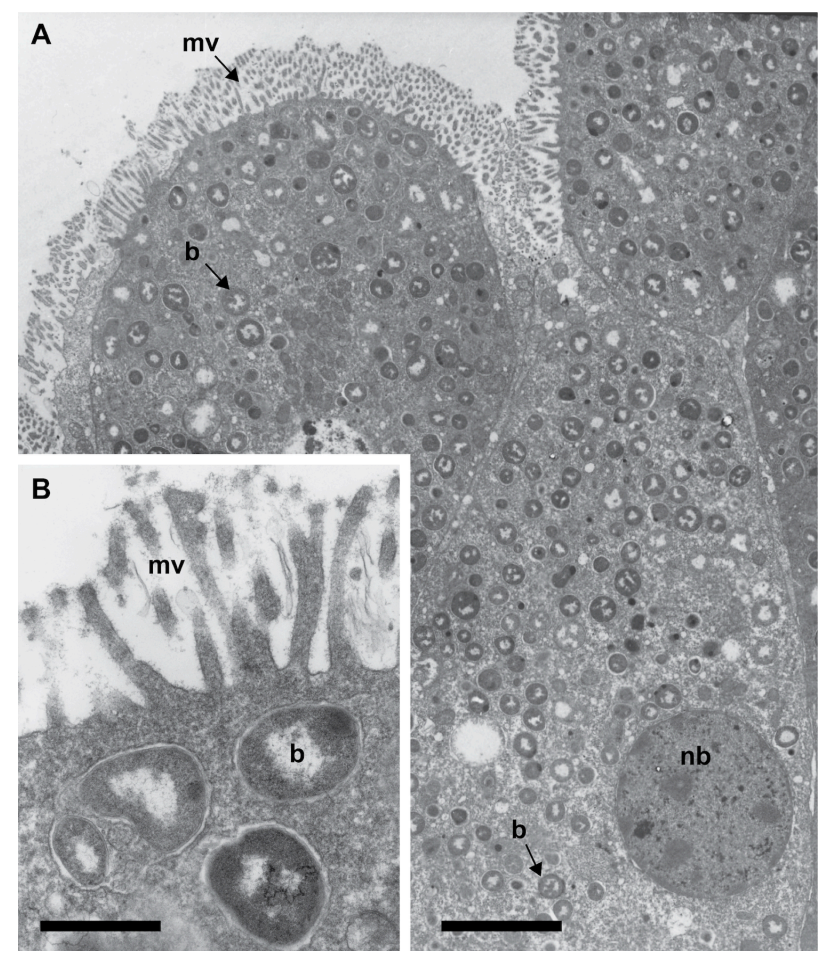

Fig 1. Transmission electron micrographs of Candidatus R. magnifica within host bacteriocytes. (A) Bacteriocyte containing many small $(0.3 \mu \mathrm{m})$ coccoid-shaped symbionts. Scale bar $=5 \mu \mathrm{m}$. (B) Higher magnification. Scale bar $=0.4 \mu \mathrm{m} . \mathrm{mv}=\mathrm{mi}-$ crovilli, $\mathrm{nb}=$ bacteriocyte nucleus, $\mathrm{b}=$ Candidatus $\mathrm{R}$. magnifica. (figure adapted from Cavanaugh [1983]). 
Table 1. Classification and general features of $C$. Ruthia magnifica according to the MIGS recommendations.

\begin{tabular}{|c|c|c|c|}
\hline MIGS ID & Property & Term & Evidence code $^{\mathrm{a}}$ \\
\hline MIGS-2 & Current classification & $\begin{array}{ll}\text { Domain } & \text { Bacteria } \\
\text { Phylum } & \text { Proteobacteria } \\
\text { Class } & \text { Gammaproteobacteria } \\
\text { Gammaproteobacteria unclassified } \\
\text { sulfur-oxidizing symbionts } \\
\text { Candidatus Ruthia magnifica }\end{array}$ & TAS[9] \\
\hline & Gram stain & negative & NAS \\
\hline & Cell shape & coccus & $\operatorname{TAS}[4,5]$ \\
\hline & Motility & none & $\operatorname{TAS}[4,5]$ \\
\hline & Sporulation & nonsporulating & NAS \\
\hline & Temperature range & mesophile & NAS \\
\hline & Optimum temperature & unknown & \\
\hline & Carbon source & $\mathrm{CO}_{2}$ & TAS[6] \\
\hline & Energy source & $\mathrm{H}_{2} \mathrm{~S}$ (Chemoautotroph) & TAS[6] \\
\hline & Terminal electron receptor & & TAS[6] \\
\hline MIGS-6 & Habitat & $\begin{array}{l}\text { endosymbiont, marine, host, } \\
\text { hydrothermal vents }\end{array}$ & $\operatorname{TAS}[3,4,5]$ \\
\hline MIGS-6.3 & Salinity & $\sim 34.6$ pps & NAS \\
\hline MIGS-22 & Oxygen & aerobic & TAS $[4,9]$ \\
\hline MIGS-15 & Biotic relationship & symbiotic & TAS $[4,9]$ \\
\hline MIGS-14 & Pathogenicity & $\begin{array}{l}\text { none } \\
\text { 9-North, East Pacific Rise, }\end{array}$ & NAS \\
\hline MIGS-4 & Geographic location & Hydrothermal vents & \\
\hline MIGS-5 & Sample collection time & December 2004 & TAS [9] \\
\hline MIGS-4.1 & Latitude & $9^{\circ} 51^{\prime} \mathrm{N}$ & NAS \\
\hline MIGS-4.2 & Longitude & $104^{\circ} 18^{\prime} \mathrm{W}$ & \\
\hline MIGS-4.3 & Depth & $\sim 2500 \mathrm{~m}$ & NAS \\
\hline
\end{tabular}

a) Evidence codes - IDA: Inferred from Direct Assay; TAS: Traceable Author Statement (i.e., a direct report exists in the literature); NAS: Non-traceable Author Statement (i.e., not directly observed for the living, isolated sample, but based on a generally accepted property for the species, or anecdotal evidence). These evidence codes are from the Gene Ontology project [13].

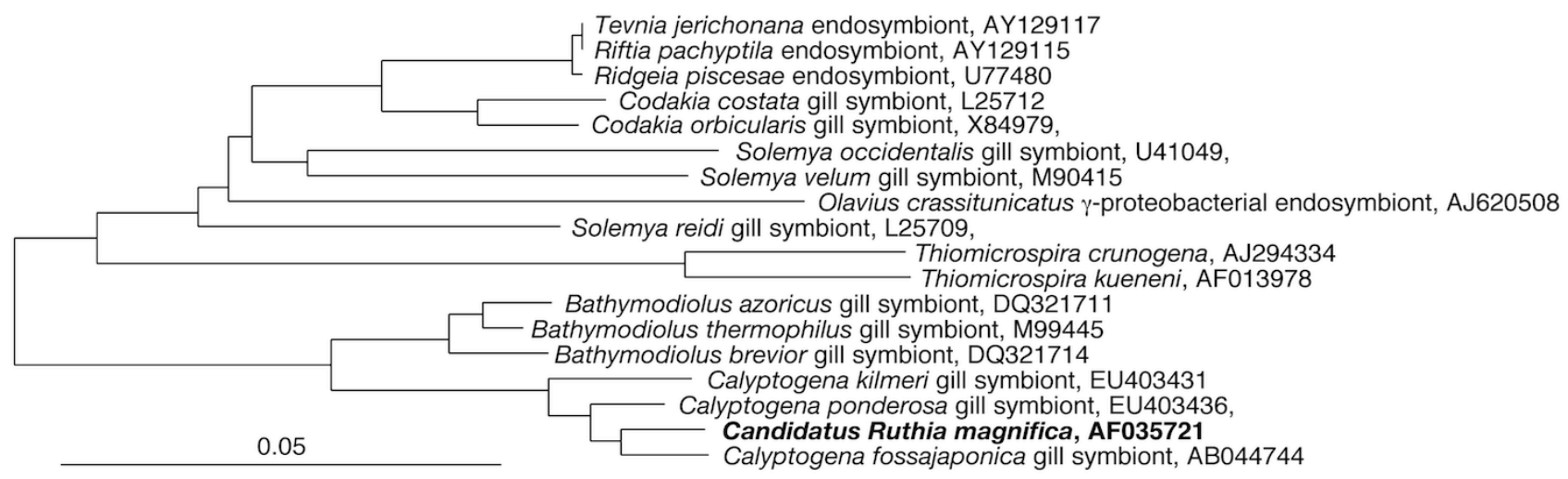

Fig 2. Phylogenetic tree inferred from complete $16 \mathrm{~S}$ rRNA gene sequences of Candidatus R. magnifica, several chemoautotrophic symbionts of marine invertebrates, and two 'freeliving' Thiomicrospira species. The tree was calculated using the Neighbor-Joining algorithm with Kimura 2-parameter correction. The tree was rooted with Fusobacterium perfoetens (M58684), which was pruned from the tree. 


\section{Project history}

The Calyptogena magnifica symbiont Candidatus Ruthia magnifica was selected for sequencing because this symbiosis is one of the dominant macrofauna at vent sites in the eastern Pacific Ocean. Knowledge of the metabolic capabilities of this symbiosis provides new perspectives on the coupling of carbon and sulfur fluxes in the deepsea, a substantial reservoir in the global carbon cycle. In addition, this genome provides insights into the origin and evolution of autotrophic endo- symbiosis. This project was funded by a US Department of Energy as part of the Joint Genome Institute Community Sequencing Program.

The complete genome sequence was finished in January 2006 and originally described in Newton et al. 2007 [9]. The GenBank accession number for the symbiont genome is CP000488.1 and is listed in the Genomes OnLine Database (GOLD) as project Gc00468. A summary of the project information is shown in Table 2.

Table 2. Project information

\begin{tabular}{lll}
\hline MIGS ID & Property & Term \\
\hline MIGS-31 & Finishing quality & Finished \\
MIGS-28 & Libraries used & $3 \mathrm{~kb}$ pUC, 8kb pMCL, and fosmid \\
MIGS-29 & Sequencing platforms & Sanger: ABI3730 \\
MIGS-31.2 & Fold coverage & $\sim 14 \times$ \\
MIGS-30 & Assemblers & Parallel phrap \\
MIGS-32 & Gene calling method & Glimmer \\
& Sequencing Center & DOE Joint Genome Institute \\
& Funding Agency & DOE \\
& Genome Database release & March 1, 2007 \\
& Genbank ID & CP000488.1 \\
& NCBI project ID & 16841 \\
& Genbank Date of Release & November 29, 2006 \\
& GOLD ID & Gc00468 \\
& & Vent ecosystems, Chemosynthetic \\
& Project relevance & symbiosis, \\
& & Environmental microbiology \\
\hline
\end{tabular}

\section{Specimen collection and DNA extraction}

Calyptogena magnifica clams were collected using DSV Alvin at the East Pacific Rise, $9^{\circ} \mathrm{N}$ vent field, during a cruise on the R/V Atlantis in December 2004. Symbiont containing gills were dissected out of the clams, frozen in liquid nitrogen, and kept at $-80^{\circ} \mathrm{C}$ until processed in the lab. Gill tissues were ground in liquid nitrogen, placed in lysis buffer $(20 \mathrm{mM}$ EDTA, $10 \mathrm{mM}$ Tris- $\mathrm{HCl}, \mathrm{pH}$ 7.9, 0.5 $\mathrm{mg} / \mathrm{ml}$ lysozyme, $1 \%$ Triton X-100, $200 \mathrm{mM} \mathrm{NaCl}$, $500 \mathrm{mM}$ guanidine- $\mathrm{HCl}$,) and incubated at $40^{\circ} \mathrm{C}$ for $2 \mathrm{hr}$. After subsequent RNase $\left(20 \mu \mathrm{g} / \mathrm{ml}, 37^{\circ} \mathrm{C}, 30\right.$ $\min )$ and proteinase $\mathrm{K}(20 \mu \mathrm{g} / \mathrm{ml}, 9(6) 1.5 \mathrm{hr})$ treatments, the samples were centrifuged and the supernatant was transferred onto Qiagen Genomic Tip columns and processed according to manufacturer's protocol (QIAGEN, Valencia, CA).

\section{Genome sequencing and assembly}

The genome was sequenced by Sanger sequencing of $3 \mathrm{~kb}, 8 \mathrm{~kb}$ and fosmid libraries. All general aspects of construction and sequencing performed at the JGI can be found on the IGI website.

Briefly, 22.15 Mb of phred Q20 sequence were generated: $9.43 \mathrm{Mb}$ from 13,755 reads from the small insert pUC library, $8.79 \mathrm{Mb}$ from 13,824 reads from the medium insert pMCL library, and $3.93 \mathrm{Mb}$ from 9,216 reads from the fosmid 
library. The DNA sequences derived from the Candidatus Ruthia magnifica libraries were estimated to be $20 \%$ contaminated with the Calyptogena magnifica host genome. Although this level of contamination could confound finishing efforts, the bacterial genome was readily identifiable in this study. The 36,795 sequencing reads were blasted against a database containing all mollusk sequences available in Genbank and the $4 \times$ draft gastropod Lottia gigantea genome sequence available at the JGI. A total of 498 reads were removed based on hits to this mollusk database.

The remaining 24,595 reads were base called, vector trimmed, and assembled using parallel phrap. One large, bacterial scaffold containing the Candidatus R. magnifica 16S rRNA gene resulted. The R. magnifica scaffold consisted of only 2 contigs spanned by 33 fosmid clones, contained 17,307 reads, 1,156,121 consensus bp, was covered by an average read depth of $14 \times$, and had a G+C content of $34 \%$. The next largest scaffold was only $29 \mathrm{~kb}$ long, with an average read depth of $\sim 7 x$ and an average $\mathrm{G}+\mathrm{C}$ content of $55 \%$. BLASTn indicated that this latter scaffold encoded ribosomal genes closely related to those of Caenorhabditis briggsae and its binning (based on GC content and read depth) with a small scaffold containing the $C$. magnifica $18 \mathrm{~S}$ rRNA gene confirmed its eukaryotic host origin.

\section{Genome annotation}

The DNA sequence was submitted to the TIGR auto-annotation pipeline (currently hosted at JCVI). Included in the pipeline is gene finding with Glimmer [14], Blast-extend-repraze (BER) searches, HMM searches, TMHMM searches, SignalP predictions, and automatic annotations from AutoAnnotate. The output from the TIGR Annotation Service was transferred to a MySQL database. Additional gene prediction analysis and manual functional annotation was performed using Manatee (http://manatee.sourceforge.net) [9].

\section{Metabolic network analysis}

The metabolic Pathway/Genome Database (PGDB) was computationally generated by the Pathologic program using Pathway Tools software version 14.0 [15] and MetaCyc version 13.1 [16], based on annotated EC numbers and a customized enzyme name mapping file. The PGDB has not been subjected to manual curation and may contain errors.

\section{Genome properties}

The genome consists of one circular chromosome with 1,160,782 bp (Figure 3). For the complete genome, 1,118 genes were predicted, 1076 of which are protein-coding genes. 837 of the protein coding genes were assigned to a putative function with the remaining annotated as hypothetical proteins. The properties and the statistics of the genome are summarized in Table 3. The distribution of genes into COG functional categories is presented in Table 4. A cellular overview diagram is presented in Figure 4, followed by a summary of metabolic network statistics shown in Table 5.

\section{Insights from the genome sequence}

The Candidatus R. magnifica genome has revealed striking differences between the chemosynthetic endosymbiont genomes and those of other obligate mutualistic symbionts for which genomic data are available. The genome is small $(1.1 \mathrm{Mb})$ and has a low $\mathrm{G}+\mathrm{C}$ content $(34 \%)$ compared to free-living sulfur oxidizing proteobacteria [9]. These common features of endosymbionts are likely the result of genome reduction and accumulation of point mutations that occur over evolutionary time across diverse symbiont species [17]. This trend has been observed in recently evolved symbioses such the insect endosymbionts (30-250 Ma) [18], as well as in chloroplasts $(\sim 1,800-2,100 \mathrm{Ma})[19]$.

However, Candidatus R. magnifica stands out in that its genome is relatively large for a maternally transmitted endosymbiont. For example, the genomes of the Gammaproteobacterial Buchnera which are endosymbionts of aphids, are $\sim 85 \%$ smaller than closely related free-living species like E. coli. In contrast, the genome of Candidatus R. magnifica is $\sim 24 \%$ the size of E. coli $\mathrm{K} 12$ and $\sim 55 \%$ smaller than Thiomicrospira crunogena, a freeliving, Gammaproteobacterial, sulfur-oxidizing chemoautotroph isolated from vents [20].

The genome lacks any form of mobile DNA content. Neither transposon- nor phage-related sequences were identified except for the putative prophage repressor gene LexA (EC 3.4.21.88). 


\section{Map of chromosome}

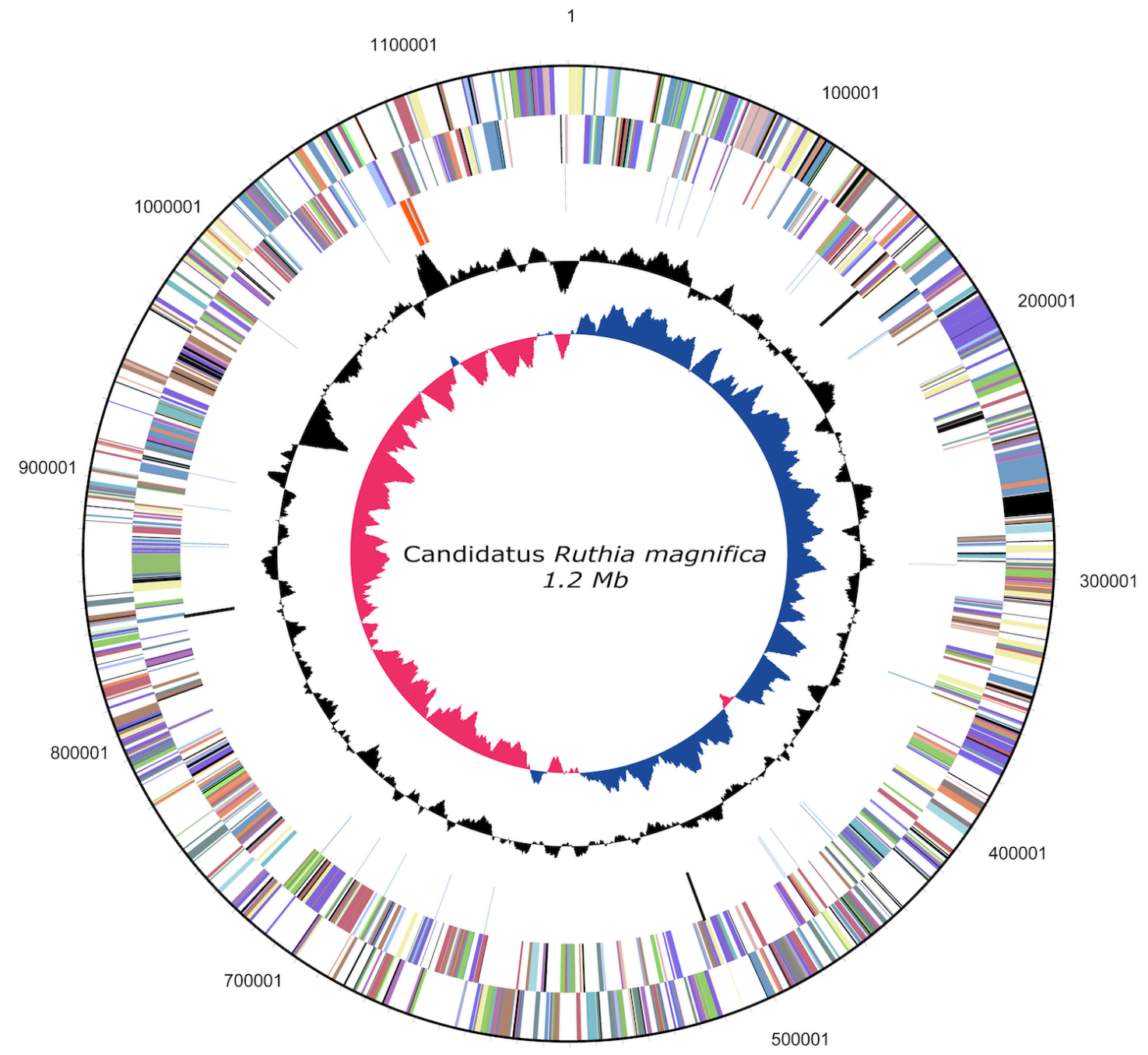

600001

\section{COG Code and COG Function Definition}

\begin{tabular}{|c|c|}
\hline$[\mathrm{A}]$ & RNA processing and modification \\
\hline [B] & Chromatin structure and dynamics \\
\hline & Energy production and conversion \\
\hline & $\begin{array}{l}\text { Cell cycle control, cell division, } \\
\text { chromosome partitioning }\end{array}$ \\
\hline & Amino acid transport and metabolism \\
\hline & Nucleotide transport and metabolism \\
\hline & Carbohydrate transport and metabolism \\
\hline & Coenzyme transport and metabolism \\
\hline & Lipid transport and metabolism \\
\hline & $\begin{array}{l}\text { Translation, ribosomal structure and } \\
\text { biogenesis }\end{array}$ \\
\hline & Transcription \\
\hline & Replication, recombination and repair \\
\hline & Cell wall/membrane/envelope biogenesis \\
\hline & Cell motility \\
\hline
\end{tabular}

[O] Posttranslational modification, protein turnover, chaperones

[P] Inorganic ion transport and metabolism

[Q] Secondary metabolites biosynthesis,

transport and catabolism

[R] General function prediction only

[S] Function unknown

[T] Signal transduction mechanisms

[U] Intracellular trafficking, secretion, and vesicular transport

[V] Defense mechanisms

[W] Extracellular structures

[Y] Nuclear structure

[Z] Cytoskeleton

NA Not assigned

Fig. 3. A circular representation of the Candidatus R. magnifica genome. The innermost and second circle highlight GC skew and GC content (\%) respectively. The third circle shows RNA genes (tRNAs blue, rRNAs orange, other RNAs black). The fourth and fifth circles show the distribution of genes on the reverse and forward strand respectively (colored by COG categories). 


\begin{tabular}{lrr}
\multicolumn{3}{l}{ Table 3. Nucleotide content and gene count levels of the genome } \\
\hline Attribute & Value & Total $^{\mathbf{a}}$ \\
\hline Genome size (bp) & 1160782 & 100 \\
DNA G+C content (bp) & 395054 & 34.0 \\
DNA coding region (bp) & 976503 & 84.1 \\
Total genes & 1118 & 100 \\
RNA genes & 42 & 3.8 \\
rRNA genes & 3 & 0.3 \\
tRNA genes & 36 & 3.2 \\
Other RNA genes & 3 & 0.3 \\
Protein-coding genes & 1076 & 96.2 \\
Protein coding genes with function prediction & 837 & 74.9 \\
Genes in paralog clusters & 243 & 21.7 \\
Protein coding genes connected to KEGG pathways & 496 & 44.4 \\
Genes assigned to COGs & 932 & 83.4 \\
Genes with signal peptides & 131 & 11.7 \\
Genes with transmembrane helices & 224 & 20.0 \\
CRISPR repeats & 0 & 0 \\
\hline
\end{tabular}

a) The total is based on either the size of the genome in base pairs or the total number of protein coding genes in the annotated genome.

The genome encodes enzymes specific for carbon fixation via the Calvin cycle; including a form II ribulose 1,5-bisphosphate carboxylase-oxygenase (RuBisC0, EC 4.1.1.39) and phosphoribulokinase (EC 2.7.1.19) [9]. Energy for carbon fixation appears to be derived from sulfur oxidation via the "sulfur oxidation (sox) pathway" and dsr (dissimilatory sulfite reductase) pathway [9].

Remarkably, the genome lacks the Calvin cycle homologs sedoheptulose 1,7-bis-phosphatase (SBPase, EC 3.1.3.37) and fructose 1,6-bis-phosphatase (FBPase, EC 3.1.3.11), suggesting that the regeneration of ribulose 1,5-bisphosphate may not follow conventional pathways [9]. Instead, the genome contains a reversible pyrophosphate-dependent phosphofructokinase (EC 2.7.1.90) homolog that may be used to generate fructose 6-phosphate [21].

The central intermediary metabolism of Candidatus R. magnifica produces all the intermediates necessary for the synthesis of amino acids, nucleotides, fatty acids, vitamins and cofactors, which are thought to be supplied to the host [9]. Notably, the symbiont lacks homologs of fumarate reductase, succinate dehydrogenase, and succinyl-coA synthase. However, the genome encodes isocitrate lyase, part of the glyoxylate shunt, suggesting succinate production from isocitrate [22].

Although able to synthesize 10 vitamins/cofactors, the cobalamin (B12) biosynthesis pathway is conspicuously absent [9]. Since cobalamin is a cofactor for methionine synthase [23] and since Candidatus R. magnifica encodes a cobalamin-independent methionine synthase, the host might not require cobalamin.

Several transporters involved in chemoautotrophy (sulfate exporters), nitrogen assimilation (nitrate and ammonium transporters), inorganic compounds (TrkAH, MgtE family, CaCA family and PiT family), and heavy metals (ZnuABC, RND superfamily, iron permeases) were identified [9].

The diverse metabolic capabilities of Candidatus R. magnifica, inferred from the genome sequence, confirm and extend our understanding of host nutritional dependency. 
Table 4. Number of genes associated with the general COG functional categories

\begin{tabular}{|c|c|c|c|}
\hline Code & Value & \%age & Description \\
\hline J & 137 & 13.50 & Translation, ribosomal structure and biogenesis \\
\hline A & 1 & 0.10 & RNA processing and modification \\
\hline K & 32 & 3.15 & Transcription \\
\hline $\mathrm{L}$ & 61 & 6.01 & Replication, recombination and repair \\
\hline B & 0 & 0.0 & Chromatin structure and dynamics \\
\hline $\mathrm{D}$ & 13 & 1.28 & Cell cycle control, mitosis and meiosis \\
\hline Y & 0 & 0.0 & Nuclear structure \\
\hline V & 9 & 0.89 & Defense mechanisms \\
\hline $\mathrm{T}$ & 17 & 1.67 & Signal transduction mechanisms \\
\hline M & 73 & 7.19 & Cell wall/membrane biogenesis \\
\hline $\mathrm{N}$ & 0 & 0.0 & Cell motility \\
\hline Z & 0 & 0.0 & Cytoskeleton \\
\hline W & 0 & 0.0 & Extracellular structures \\
\hline$U$ & 24 & 2.36 & Intracellular trafficking and secretion \\
\hline $\mathrm{O}$ & 74 & 7.29 & Posttranslational modification, protein turnover, chaperones \\
\hline $\mathrm{C}$ & 90 & 8.87 & Energy production and conversion \\
\hline G & 31 & 3.05 & Carbohydrate transport and metabolism \\
\hline $\mathrm{E}$ & 99 & 9.75 & Amino acid transport and metabolism \\
\hline $\mathrm{F}$ & 39 & 3.84 & Nucleotide transport and metabolism \\
\hline $\mathrm{H}$ & 94 & 9.26 & Coenzyme transport and metabolism \\
\hline I & 36 & 3.55 & Lipid transport and metabolism \\
\hline$P$ & 45 & 4.43 & Inorganic ion transport and metabolism \\
\hline Q & 11 & 1.08 & Secondary metabolites biosynthesis, transport and catabolism \\
\hline $\mathrm{R}$ & 77 & 7.59 & General function prediction only \\
\hline S & 52 & 5.12 & Functions unknown \\
\hline- & 186 & 16.64 & Not in COGs \\
\hline
\end{tabular}

a) The total is based on the total number of protein coding genes in the annotated genome. 


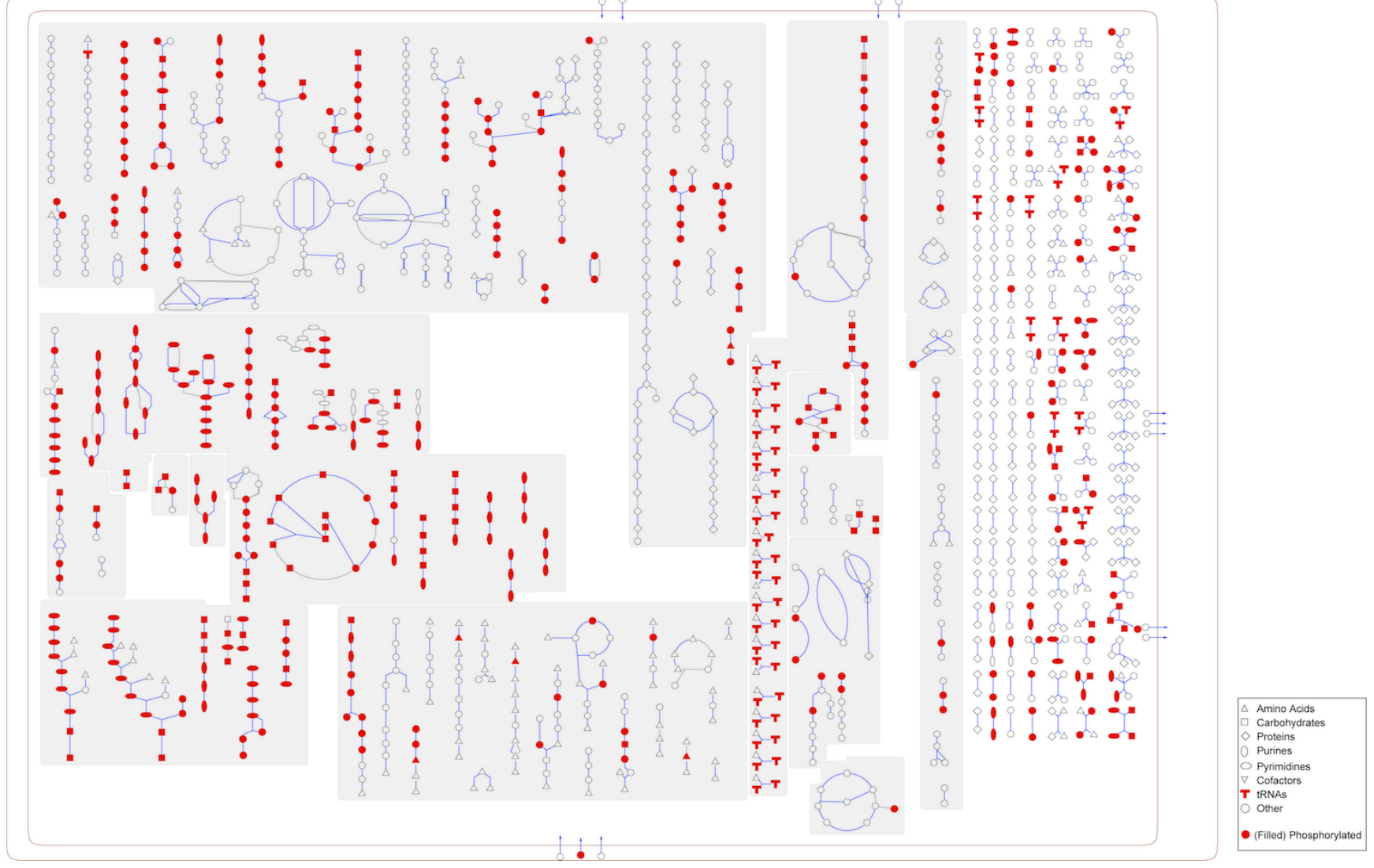

Figure 4. Schematic cellular overview of all pathways of Candidatus R. magnifica generated using Pathway Tools software version 14.0 [15]. Nodes represent metabolites, with shapes indicating classes of metabolites. Lines represent reactions.

Table 5. Metabolic Network Statistics

\begin{tabular}{lr}
\hline Attribute & Value \\
\hline Total genes & 1117 \\
Enzymes & 430 \\
Enzymatic reactions & 702 \\
Pathways & 115 \\
Metabolites & 565 \\
\hline
\end{tabular}

\section{Acknowledgements}

This research was funded by a grant from the Office of Science of the U.S. Department of Energy to CMC and JAE, a Howard Hughes Medical Institute Predoctoral Fellowship to ILGN and a Rubicon grant from the Netherlands Organisation for Scientific Research (NWO) to GR. The work was conducted in part at the U.S. De- partment of Energy Joint Genome Institute, which is supported by the Office of Science of the U.S. Department of Energy under Contract No. DE-AC0205CH11231. We thank Eddy Rubin and David Bruce for project management.

\section{References}

1. Cavanaugh CM, McKiness ZP, Newton ILG, Stewart FJ. (2006). Marine chemosynthetic symbioses. In: Dworkin M, Falkow S, Rosenberg E, Schleifer $\mathrm{KH}$ and Stackebrandt E (eds). The Prokaryotes.

Third Edition. A Handbook on the Biology of Bacteria. Springer: New York. pp 475-507.

2. Peek A, Gustafson R, Lutz R, Vrijenhoek R. Evolutionary relationships of deep-sea hydrothermal vent and cold-water seep clams (Bivalvia: Vesi- 
comyidae): Results from the mitochondrial cytochrome oxidase subunit I. Mar Biol 1997;

130:151-161. doi:10.1007/s002270050234

3. Boss KJ, Turner RD. The giant white clam from the Galapagos Rift, Calyptogena magnifica n. sp. (Bivalvia; Vesicomyidae). Malacologia 1980; 20:161-194.

4. Cavanaugh CM. Symbiotic Chemoautotrophic Bacteria in Marine-Invertebrates from Sulfide-Rich Habitats. Nature 1983; 302:58-61. doi:10.1038/302058a0

5. Felbeck H, Somero GN. Primary Production in Deep-Sea Hydrothermal Vent Organisms - Roles of Sulfide-Oxidizing Bacteria. Trends Biochem Sci 1982; 7:201-204. doi:10.1016/09680004(82)90088-3

6. Fisher CR, Childress JJ, Arp AJ, Brooks JM, Distel DL, Dugan JA, Felbeck H, Fritz LW, Hessler RR, Johnson $\mathrm{KS}$, et al. Variations in the hydrothermalvent clam Calyptogena magnifica at the Rose Garden vent on the Galapagos Spreading Center. Deep-Sea Res 1988; 35:1811-1831. doi:10.1016/0198-0149(88)90051-9

7. Kuwahara H, Yoshida T, Takaki Y, Shimamura S, Nishi S, Harada M, Matsuyama K, Takishita K, Kawato M, Uematsu K, et al. Reduced genome of the thioautotrophic intracellular symbiont in a deep-sea clam, Calyptogena okutanii. Curr Biol 2007; 17:881-886. PubMed doi:10.1016/j.cub.2007.04.039

8. Newton IL, Girguis PR, Cavanaugh CM. Comparative genomics of vesicomyid clam (Bivalvia: Mollusca) chemosynthetic symbionts. BMC Genomics 2008; 9:585. PubMed doi:10.1186/14712164-9-585

9. Newton IL, Woyke T, Auchtung TA, Dilly GF, Dutton RJ, Fisher MC, Fontanez KM, Lau E, Stewart FJ, Richardson PM, et al. The Calyptogena magnifica chemoautotrophic symbiont genome. Science 2007; 315:998-1000. PubMed doi:10.1126/science.1138438

10. Hurtado LA, Mateos M, Lutz RA, Vrijenhoek RC. Coupling of bacterial endosymbiont and host mitochondrial genomes in the hydrothermal vent clam Calyptogena magnifica. Appl Environ Microbiol 2003; 69:2058-2064. PubMed doi:10.1128/AEM.69.4.2058-2064.2003

11. Peek AS, Feldman RA, Lutz RA, Vrijenhoek RC. Cospeciation of chemoautotrophic bacteria and deep sea clams. Proc Natl Acad Sci USA 1998; 95:9962-9966. PubMed doi:10.1073/pnas.95.17.9962
12. Stewart FJ, Young CR, Cavanaugh CM. Lateral symbiont acquisition in a maternally transmitted chemosynthetic clam endosymbiosis. Mol Biol Evol 2008; 25:673-687. PubMed doi:10.1093/molbev/msn010

13. Ashburner M, Ball CA, Blake JA, Botstein D, Butler H, Cherry JM, Davis AP, Dolinski K, Dwight SS, Eppig JT, et al. Gene ontology: tool for the unification of biology. The Gene Ontology Consortium. Nat Genet 2000; 25:25-29. PubMed doi:10.1038/75556

14. Delcher AL, Harmon D, Kasif S, White O, Salzberg SL. Improved microbial gene identification with GLIMMER. Nucleic Acids Res 1999;

27:4636-4641. PubMed doi:10.1093/nar/27.23.4636

15. Karp PD, Paley S, Romero P. The Pathway Tools software. Bioinformatics 2002; 18(Suppl 1):S225S232. PubMed

16. Caspi R, Foerster H, Fulcher CA, Kaipa P, Krummenacker M, Latendresse M, Paley S, Rhee SY, Shearer AG, Tissier C, et al. The MetaCyc Database of metabolic pathways and enzymes and the BioCyc collection of Pathway/Genome Databases. Nucleic Acids Res 2007; 36:D623-D631. PubMed doi:10.1093/nar/gkm900

17. Wernegreen JJ. For better or worse: genomic consequences of intracellular mutualism and parasitism. Curr Opin Genet Dev 2005; 15:572-583. PubMed doi:10.1016/j.gde.2005.09.013

18. Gil R, Sabater-Munoz B, Latorre A, Silva FJ, Moya A. Extreme genome reduction in Buchnera spp.: toward the minimal genome needed for symbiotic life. Proc Natl Acad Sci USA 2002; 99:44544458. PubMed doi:10.1073/pnas.062067299

19. Martin W, Stoebe B, Goremykin V, Hapsmann S, Hasegawa M, Kowallik KV. Gene transfer to the nucleus and the evolution of chloroplasts. Nature 1998; 393:162-165. PubMed doi:10.1038/30234

20. Scott KM, Sievert SM, Abril FN, Ball LA, Barrett CJ, Blake RA, Boller AJ, Chain PS, Clark JA, Davis $\mathrm{CR}$, et al. The genome of deep-sea vent chemolithoautotroph Thiomicrospira crunogena XCL-2.

PLoS Biol 2006; 4:e383. PubMed doi:10.1371/journal.pbio.0040383

21. Kemp RG, Tripathi RL. Pyrophosphate-dependent phosphofructo-1-kinase complements fructose 1,6-bisphosphatase but not phosphofructokinase deficiency in Escherichia coli. I Bacteriol 1993; 175:5723-5724. PubMed 
22. Vanni P, Giachetti E, Pinzauti G, McFadden BA. Comparative structure, function and regulation of isocitrate lyase, an important assimilatory enzyme. Comp Biochem Physiol B 1990; 95:431458. PubMed doi:10.1016/0305-0491(90)90002B
23. Keseler IM, Collado-Vides J, Gama-Castro S, Ingraham J, Paley S, Paulsen IT, Peralta-Gil M, Karp PD. EcoCyc: a comprehensive database resource for Escherichia coli. Nucleic Acids Res 2004; 33:D334-D337. doi:10.1093/nar/gki108 